\title{
Eventration of Diaphragm: A Case Seriesreport
}

\author{
Sahil Sharma ${ }^{1}$,Sanjay Pandey ${ }^{2}$,Yashpal Monga ${ }^{3}$, Akshay Baid $^{1}$,Prateek Bansal ${ }^{1}$, \\ Syamantak Srivastava ${ }^{1}$. \\ ${ }^{I} 3^{\text {rd }}$ Year Resident Department Of General Surgery, Subharti Medical College \\ ${ }^{2}$ Professor, Department Of General Surgery, Subharti Medical College \\ ${ }^{3}$ Professor \& HOD, Department Of General Surgery, Subharti Medical College.
}

\begin{abstract}
Eventration of the diaphragm is generally regarded as a condition in which the left or the right leaf of the diaphragm has ascended abnormally high into the chest. In rare cases both leaves are elevated.Congenital eventration of diaphragm is due to maldevelopment of muscular portion of the hemidiaphragm. Acquired eventration is usually the result of a injury to the roots of the phrenic nerve. This entity is most often is incidentally detected on chest radiographs and frequently asymptomatic. It usually is identified at young years of life its diagnosis in a mature or old patients is rare. We here are presenting a case report series of 3 patients with respiratory distress and variable symptoms due to Eventration of diaphragm with gastric volvulus.
\end{abstract}

\section{Introduction}

Diaphragmatic eventration is defined as a permanent elevation of a hemidiaphragm without defects of continuity. The muscular insertions are normal, the normal orifices are sealed and there is no interruption of the pleural or peritoneal layers. ${ }^{[1]}$ Clinical manifestations range from asymptomatic to life threatening respiratory distress. Recurrent chest infections are also the presenting complaints in patients. Gastrointestinal symptoms may be present if there is migration of abdominal viscera into the thoracic cavity. ${ }^{[2]}$ Eventration can be classified into two groups, congenital (non-paralytic) and acquired (paralytic).Congenitaleventration is the result of incomplete development of the muscular portion of the diaphragm. ${ }^{[3]}$ Similar to true aplasia,the majority of the diaphragm is replaced by a thin fibrousmembrane with a narrow muscular rim attached in thenormal position. ${ }^{[4]}$ The cause of this failure is not known but it has been found in cases of fetal rubella and cytomegalovirus infection ${ }^{[3]}$ and in babies with trisomic chromosomal abnormalities. In congenitaleventration, the phrenic nerve is normal.

Acquired eventration is usually the result of a traction injury to the roots of the phrenic nerve during traumatic breech delivery, resulting in actual tearing of the roots in severe cases. Paralysis caused by direct pressure on the phrenic nerve by forceps applied to the neck carries a better prognosis. ${ }^{[3][5]}$ In older infants and children the commonest cause of phrenic nerve palsy is injury during cardiac surgery ${ }^{[6]}$ The first report of a surgical repair was published by Morrison in $1923 .{ }^{[7]}$ It is a rare anomaly with an incidence of 1 in 10,000 live births.

Recurrent chest infections are the commonest presenting complaint in patients ${ }^{[8]}$. We here are presenting a case report series of patients with respiratory distress and variable symptoms due to Eventration of diaphragm with gastric volvulus.

Case 1:

A 65 year old lady presented to medicine OPD with cough, difficulty in breathing, respiratory distress, chest pain left side, pain in abdomen and vomiting. Initially pain in chest and abdomen increased with taking food orally. On examination PR-94 pm temp. - 100 F, B.p.-150/100, wt. - $124 \mathrm{~kg}$. No features of clubbing, cyanosis, icterus, pallor and lymphadenopathy was seen.

On chest examination respiratory movements were decreased on left side, tactile vocal fremitus was decreased and note was impaired on left side. Breath sounds were decreased in left inframammary, left infra axillary and infrascapular areas. Lab investigations were with in normal limits. Chest X-ray was done which showed elevated left dome of diaphragm, haziness is present in lower zone left side right dome of diaphragm was normal in position and contour. Left diaphragmatic eventration or left diaphragmatic palsy was suspected hence the patient was transferred to surgery department.She was further evaluated the patient and barium meal with CECT chest was ordered. Barium meal showed eventration of left dome of diaphragm with organoaxial volvulus (gastric volvulus).

CECT Chest concluded and confirmed the findings of left diaphragmatic eventration with gastric volvulus.Fluoroscopy along with sniff test suggested its cause to be diaphragmatic paralysis. Then the patient was planned for surgery. We decided to go for abdominal approach in this patient. Abdomen was opened with left subcostal incision. The stomach and transverse colon were found to be densely adhered to left dome of 
diaphragm which was higher up. With meticulous dissection they were released, stomach was de-rotated and fixed with anterior abdominal wall. Plication of left hemi diaphragm was done with prolene. Post op period was uneventful. Patient was discharged after 15 days. In follow up patient was relieved of symptoms.

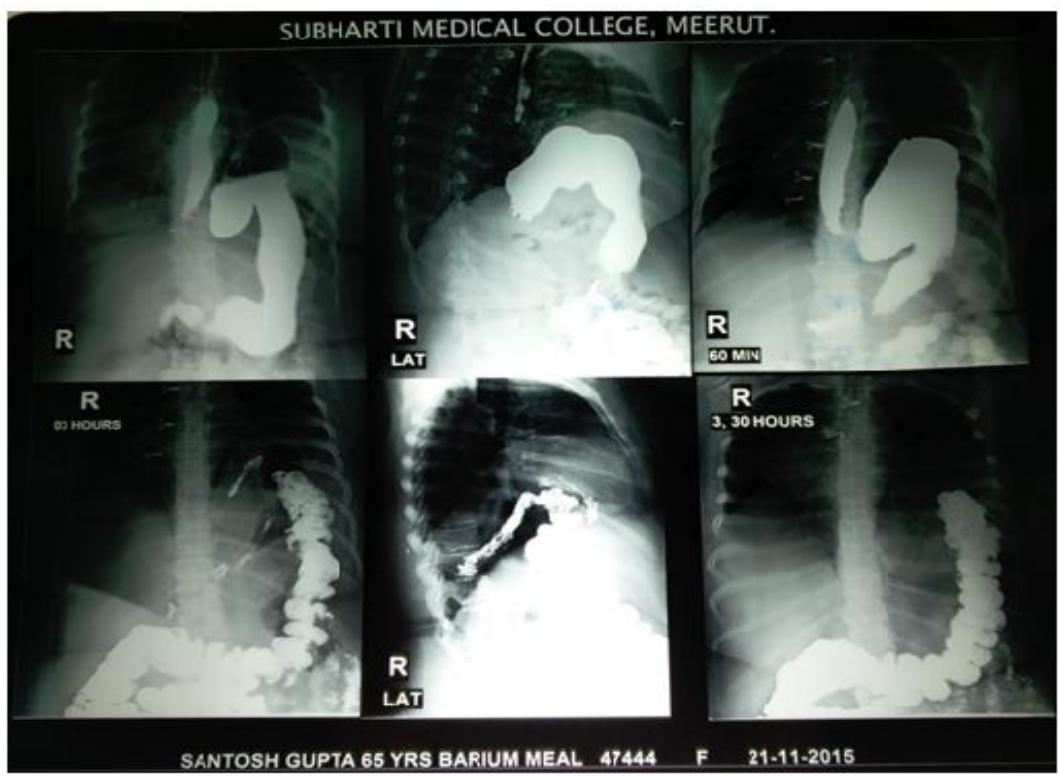

Barium meal showing eventration of left dome of diaphragm with organoaxial volvulus

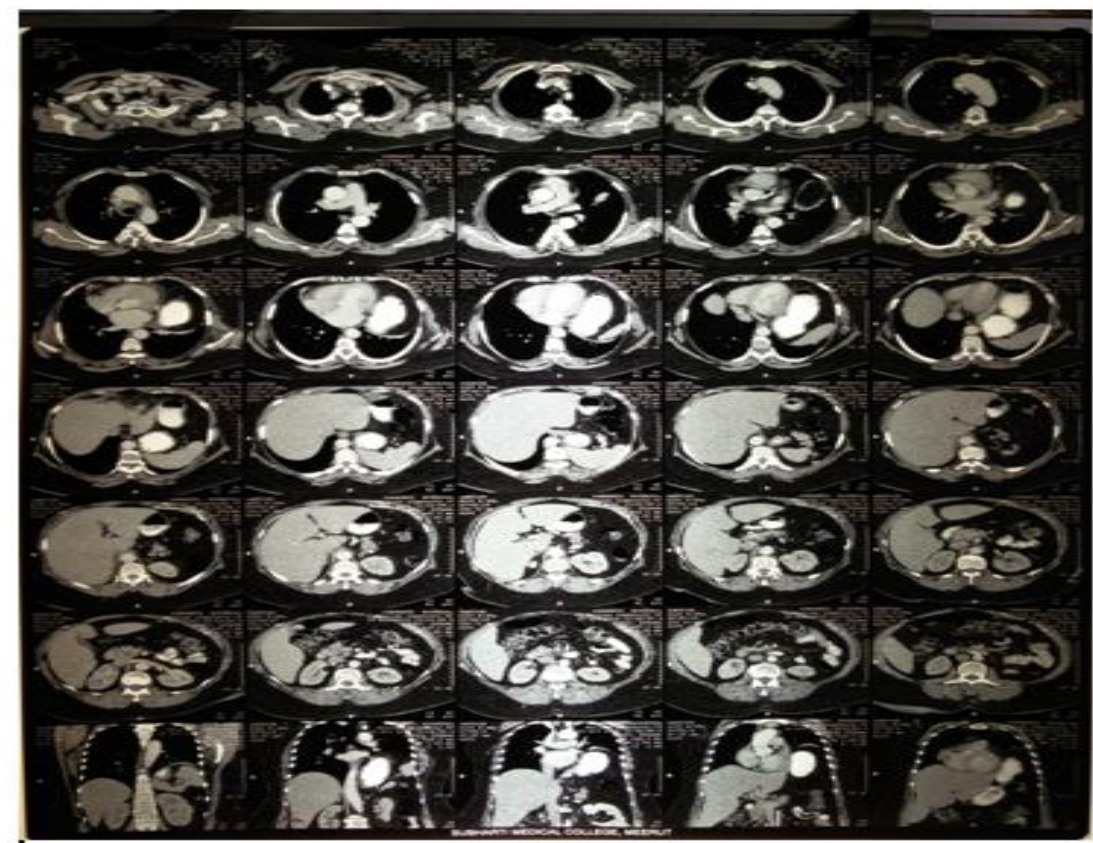

CECTChest left diaphragmatic eventration with gastric volvulus

Case 2

A 14 year old boy presented to medical outpatient department with off and on swelling in epigastrium, spherical in shape associated with pain which aggravates on taking meals and subsides on its own or may be after vomiting. Patient was kept NPO and Ryle's tube was passed with difficulty and caused decompression of stomach. Patient was referred to surgery with suspicion of Gastric Outlet Obstruction (GOO) with CECT abdomen suggestive of distended stomach with fluid level consistent with GOO (?? tubercular). There was no obstructing mass noted on CECT. Plain chest x-ray and Barium meal study were done suggestive of gastric volvulus. Exploratory laparotomy was done and left side eventration of diaphragm with gastric volvulus was found. Gastric mobilization with plication of diaphragm along with fixation of stomach with anterior abdominal 
wall was done. Post-operative period was uneventful and patient was discharged with stable vitals under satisfactory condition.

\section{Case 3}

A 50 year old lady known case of carcinoma breast came to surgery O.P.D with complains of breathlessness on exertion, difficulty in breathing more while lying down since 3 years and pain in abdomen with vomiting since 5days.Patient was admitted, examined and investigated. Abdomen was soft, bowel sounds present, no visible or palpable lump or swelling in abdomen and vitally stable. This patient had reduced breath sounds on right side of chest. Plain chest $\mathrm{x}$ ray showed elevation of left dome of diaphragm. To confirm the suspected diagnosis CECT chest was ordered and it confirmed eventration of left side of diaphragm. Fluoroscopy along with sniff test suggested its cause to be diaphragmatic paralysis. Left subcostal incision was given stomach and bowel were retracted from chest cavity. Stomach was fixed with anterior abdominal wall and plication of diaphragm was done. Intra op and post op period was uneventful. Patient was discharged on $17^{\text {th }}$ day of surgery after her symptoms were relieved.

\section{Discussion}

Eventration of the diaphragm is a condition in which all or part of the diaphragm is largely composed of fibrous tissue with only a few or no interspersed muscle fibers. It is usually congenital but may be acquired ${ }^{[9]}$ Complete eventration of diaphragm invariably occurs on the left side but partial eventration of the diaphragm occurs virtually on the right side. ${ }^{[10]}$ Eventration of diaphragm is generally asymptomatic in adults and is discovered incidentally on normal screening of chest X-ray. Symptoms may be present in obese patients as a result of raised intra-abdominal pressure as it was incase 1 . These symptoms can be related to gastrointestinal tract, respiratory embarrassment, and rarely cardiac dysfunction, have been attributed to the anomaly ${ }^{[1]}$ which were all present in our case 1 .In this case patient had respiratory distress chest pain,pain in abdomen with vomiting and was having CHF features. Elevation of diaphragm can also be attributed to interruption of phrenic nerve by neoplasm or surgical resection. In adults it is very difficult or impossible to distinguish it from diaphragmatic paralysis.

These entities can be distinguished radiologically. In adults the diagnosis of diaphragmatic eventration can usually be made on standard PA and lateral chest films. ${ }^{[12]}$

In the PA projection, the elevated diaphragm forms a round unbroken line arching from the mediastinum to the costal arch. Conventional chest radiography has been found to be a useful modality for assessment of the functional status of an elevated diaphragm as the evaluation of the shape of an elevated diaphragm may preclude the need for fluoroscopic sniff test to determine diaphragmatic paralysis. ${ }^{[13]}$ Flouroscopy is considered the most reliable way to document diaphragmatic paralysis and the sniff test is necessary to confirm that abnormal hemidiaphragm excursion is due to paralysis rather than unilateral weakness. ${ }^{[14]}$

Ultrasonography can help in establishing the diagnosis of partial eventration and in distinguishing it from diaphragmatic nerve interruption. The diaphragm can be seen as a continuous thin layer above the elevated abdominal viscera and on real-time ultrasound the abnormal region can be seen to move downward with the normal portion although it may show a slight lag in its inspiratory excursion. ${ }^{[15]}$ The radiological sight of complete eventration is identical to that diaphragmatic paralysis. In some cases, however, there is no way of knowing whether elevation is caused by congenital absence of muscle or by phrenic paralysis. ${ }^{[16]}$

CECT chest nearly confirms the diagnosis of eventration of diaphragm along with difference in normal anatomy on both sides.It also helps to confirm if abdominal contents are present in chest cavity, diaphragm leaves intact or not, any other underlying pathology causing similar symptoms as eventration of diaphragm. Barium meal study done to recognize any delineated anatomy of stomach or bowel due to eventration such as gastric volvulus in two of our cases.

In gastric volvulus, the etiology of the rotation is either primary or secondary. Primary refers to the absence of diaphragmatic defects or intra-abdominal abnormality causing the volvulus and also it may be seen in children with different ages. ${ }^{[17]}$ In $30 \%$ of gastric volvuli, there is a primary cause. Secondary gastric volvulus have alternative causes, including congenital or traumatic diaphragmatic hernias, hiatal hernias, diaphragmatic eventration, abdominal bands or adhesions. ${ }^{[18]}$ Many cases occur with a paraesophageal hernia or diaphragmatic eventration like our patients.

Diaphragmatic plication is a standard, well-described technique to treat diaphragmatic eventration ${ }^{[19]}$ but there have been only a limited number of reports published, most with small series and short follow-ups. Higgs et al. described a group of 19 patients with long-term follow-up in 15 patients ${ }^{[20]}$ and Versteegh et al. reported on 22 patients with a follow-up in $17^{[21]}$. Both clearly proved that the main and probably most important result is the significant and long-lasting improvement in the subjective symptomatology. 
In conclusion, these cases with case 1 being acquired type of eventration with organoaxial rotation of stomach (gastric volvulus), Case 2 congenital type of eventration and Case 3 acquired type of eventration without gastric Volvulus .Our experience with these cases demonstrates that patients with chronic respiratory infections due to unilateral, non-malignant eventration significantly benefit from diaphragmatic plication.

\section{References}

[1]. J. Mouroux, N. Venissac, F. Leo, M. Alifano, F. Guillot,Surgical treatment of diaphragmatic eventration using video assisted thoracic surgery: a prospective study, Ann. Thorac. Surg. 79 (2005) 308-312.

[2]. T.W. Shields, Diaphragmatic function, diaphragmatic paralysis,andeventration of the diaphragm, in: T.W. Shields, J. Locicero,R.B. Ponn, V.W. Rusch (Eds.), General Thoracic Surgery,Lippincot Williams \& Wilkins, 2005, pp. 740-745.

[3]. Irving MI, Booker PO: Eventration of the diaphragm and

[4]. diaphragmatic paralysis, In: Lister J, Irving $1 \mathrm{M}$ (eds), Neonatal

[5]. Surgery. Boston: Butterworths, pp. 213-216, 1990.

[6]. Rodgers BM, Howks P: Bilateral congenital eventration of the diaphragm: successful surgical management. J PediatrSurg

[7]. 21: 858-864, 1986

[8]. Otte JB, Mignon T, Kartheuser A, et al: Diaphragmatic eventration and paralysis in children. ActaChirBelg 82(6):

[9]. 559-68, 1982

[10]. Hualt G, Checoury A, Binet JP: Diaphragmatic paralysis and

[11]. eventration. Sem Hop 58 (35): 2027-31, 1982.

[12]. J.M.W. Morrison, Eventration of diaphragm due to unilateral phrenic nerve paralysis, Arch. Radiol. Electrotherap. 28 (1923) $72-75$.

[13]. A. Soni, P. Singh, R.J. Singh, V. Sood, Eventration of diaphragm - embryological basis, J Anat. Soc. India 54 (2005) 39-41.

[14]. Laxdale OE, McDougall H, Mellin GW. Congenital eventration of the diaphragm. N Engl Med. 1954;250:401. [PubMed]

[15]. Seaton A. Abnormalities and Diseases of the Diaphragm. In: Seaton A, Seaton D, Leitch AG, editors. Crofton and Douglas's Respiratory Diseases. 5th ed. Blackwell Science, Oxford; 2000. pp. 1234-49.

[16]. Chin EF, Lynn RB. Surgery of eventration of the diaphragm. J Indian Med. 1986;84:187

[17]. Deslauries J. Eventration of the diaphragm. Chest SurgClin North Am. 1998;8:315-30. [PubMed]

[18]. Verhey PT, Gosselin MV, Primack SL, Kraemmer AC. Differentiating diaphragmatic paralysis and eventration. ActaRadiol. 2007;14:420-5. [PubMed]

[19]. Gierada DS, Slone RM, Fleishman MJ. Imaging evaluation of the diaphragm. Chest SurgClin North Am. 1998;8:237-80. [PubMed]

[20]. Larson RK, Evans BH. Eventration of the diaphragm. Am Rev Respir Dis. 1963;87:753.

[21]. Fraser and Pare's diagnosis of diseases of the chest. 4th ed. pp. 2994-5.

[22]. Andıran F, Tanyel FC, Balkancı F, Hiçsönmez A. Acute abdomen due to gastric volvulus: Diagnostic value of a single plain radiograph. PediatrRadiol 1995; 25 Suppl 1: S240.

[23]. Chau B, Dufel S. Gastric volvulus. Emerg Med J 2007; 24: 446- 7.

[24]. T.W. Shields, Diaphragmatic function, diaphragmatic paralysis,andeventration of the diaphragm, in: T.W. Shields, J. Locicero,R.B. Ponn, V.W. Rusch (Eds.), General Thoracic Surgery, Lippincot Williams \& Wilkins, 2005, pp. 740-745.

[25]. S.M. Higgs, A. Hussain, M. Jackson, R.J. Donnelly, R.G.Berrisford, Longterm results of diaphragmatic plication for unilateral diaphragm paralysis, Eur. J. Cardiothorac. Surg. 21 (2002) 294-297.

[26]. M.I.M. Versteegh, J. Braun, P.G. Voigt, D.B. Bosman, J. Stolk, K.F. Rabe, R.A.E. Dion, Diaphragm plication in adult patients with diaphragm paralysis leads to long-term improvement of pulmonary function and level of dyspnea, Eur. J. Cardiothorac. Surg. 32 (2007) 449-456. 